\title{
PENGARUH MODAL, BIAYA PRODUKSI, JUMLAH TENAGA KERJA DAN TINGKAT PENDIDIKAN TERHADAP PENDAPATAN UMKM SEKTOR KULINER DI KECAMATAN LUBUK BEGALUNG KOTA PADANG
}

\author{
Windri Oktaviana, Ansofino, Yosi Eka Putri \\ Program Studi Pendidikan Ekonomi STKIP PGRI Sumatera Barat \\ oktavianawindri@gmail.com
}

\begin{abstract}
This study aims to analyze 1) the influence of capital on income. 2) the influence of costs on income, 3) the influence of the number of workers on income, 4) the influence of education level on income and 5) the influence of Capital, Production Costs, Number of Labor, and Education Level on Income. This type of research is descriptive and associative research. This research was conducted on micro, small and medium enterprises (MSMEs) culinary sector in Lubuk Begalung Subdistrict. Sampling using Stratified Random Sampling technique. Instruments used for research in the form of open questionnaires with the use of Multiple Linear Regression tests and hypothesis tests with t test and $F$ test. A greater influence was found in the group of micro-businesses indicated by the value of mirko's business coefficient of 0.455974 , a small business of 0.253589 . With a t-count value of micro businesses of $4.508856>t$-table of 1.99 , small business t-count of $2.029458>$ t-table of 2.02. 2) production costs have a positive and significant effect on MSME revenues. Greater influence is found in the group of micro businesses indicated by the value of the coefficient of micro enterprises is 1.593910 , small businesses amounting to 0.414613 . With a t-count value of micro businesses of 9.139478> t-table of 1.99, t-count of small businesses of 4.757485> t-table of 2.02. 3) The number of workers has a positive and insignificant effect on the income of MSMEs,. Greater influence is found in small business groups indicated by the value of the coefficient of micro enterprise is 5876951 and micro enterprise is 3981416. With a t-count value of micro businesses of $1.911951<\mathrm{t}$-table of 1.99 , small business t-count of $2.300887>\mathrm{t}$ table of 2.02. 4) The level of education has a positive and significant effect on the income of MSMEs in the culinary sector in Lubuk Begalung District. Greater influence is found in the group of micro businesses indicated by the value of the coefficient of micro enterprises is 637554.9, small businesses amounting to 2145507. With a t-count value of micro businesses of 2.223903>t-table of $1.99, \mathrm{t}-$ count of small businesses of 2.358697> t-table of 2.02. 5) There is a mutual influence of capital, production costs, the number of labor and education levels on the income of MSMEs with a value of Fhitung of 54,591 > Ftabel 2.68, and a significant value of $0.000000<0.05$.
\end{abstract}




\section{Keywords: Capital, Production Costs, Number of Workers, Culinary Sector MSME Income.}

\section{PENDAHULUAN}

Usaha Mikro, Kecil dan Menengah (UMKM) di Indonesia menurut (Utari, 2014:576) merupakan salah satu prioritas dalam pengembangan ekonomi nasional, selain karena UMKM menjadi tulang punggung sistem ekonomi kerakyatan yang tidak hanya ditujukan mengurangi masalah kesenjangan antar golongan pendapatan dan antar pelaku usaha, ataupun pengentasan kemiskinan dan penyerapan tenaga kerja. Pengembangan UMKM akan memperluas basis ekonomi dan dapat memberikan kontribusi yang signifikan dalam mempercepat struktural, yaitu meningkatkan perekonomian daerah dan ketahanan ekonomi nasional. Pembangunan usaha kecil merupakan pergerakan pembangunan nasional. Pengembangan usaha mikro kecil dan menengah (UMKM) diupayakan agar dapat menjangkau dan merata sampai daerah pedesaan.
Faktor usaha yang harus ada sebelum melakukan kegiatan bisnis adalah modal. Berkaitan dengan pentingnya modal terhadap pendapatan UMKM yaitu karena merupakan suatu dasar dalam membangun usaha dan pada umumnya menjadi kendala. Modal bisa dari diri sendiri maupun modal dari luar, contoh: pinjaman pada bank, namun pinjaman sulit diperoleh karena persyaratan dari bank (Bambang, 2010:18). Modal merupakan faktor produksi berupa benda yang diciptakan oleh manusia dan digunakan untuk memperoleh barang dan jasa-jasa yang merekaa butuhkan. Beberapa contohnya adalah sistem pengairan, jaringan jalan raya, bangunan pabrik dan pertokoan, mesin-mesin dan peralatan pabrik serta alat pengangkutnya (Sukirno, 2009:6). Hasil pengembalian investasi atau yang lebih dikenal dengan return of investment (roi) menurut (Kasmir, 2011: 202) merupakan rasio yang 
menunjukkan hasil (return) atas jumlah aktiva yang digunakan dalam perusahaan. ROI juga merupakan suatu ukuran tentang efektivitas manajemen dalam mengelola investasinya. Disamping itu, hasil pengembalian investasi menunjukkan produktivitas dari seluruh dana perusahaan, baik modal pinjaman maupun modal sendiri. Semakin kecil (rendah) rasio ini, semakin kurang baik, demikian pula sebaliknya. Arti dari rasio ini digunakan untuk mengukur efektivitas dari keseluruhan operasi perusahaan. Berikut rumus untuk mencari ROI adalah:

Dari tabel 3 diketahui kepemilikan modal sendiri paling tinggi pada tahun 2015 yaitu sebesar Rp 787.950.000, kepemilikan modal luar tertinggi tetap pada tahun 2015 yaitu sebesar Rp 464.000.000, pendapatan tertinggi terdapat pada tahun 2016 yaitu sebesar Rp 446.500.000. berdasarkan tabel diatas penggunaan modal sektor kuliner pada tahun 2015-2017 mengalami fluktuasi. Mulai dari tahun 2015 sebesar 0,035\%, kemudian ditahun 2016 terjadi peningkatan sebesar $122,05 \%$ dan mengalami penurunan pada tahun 2017 sebesar $62.86 \%$, bagi setiap usaha, baik skala kecil menengah maupun besar modal merupakan salah satu faktor yang sangat penting yang dapat menentukan tingkat

Tabel 1 Data Modal dan Pendapatan UMKM Sektor Kuliner di Kecamatan Lubuk Begalung Tahun 2015-2017

\begin{tabular}{|c|c|c|c|}
\hline \multicolumn{4}{|c|}{ Keterangan Tahun 2015 Tahun $2016 \quad$ Tahun 2017} \\
\hline $\begin{array}{l}\text { Modal } \\
\text { sendiri(Rp) }\end{array}$ & 787.950 .000 & 335.900 .000 & 546.800 .000 \\
\hline $\begin{array}{l}\text { Modal Luar } \\
\mathrm{Rp})\end{array}$ & 464.000 .000 & 78.500 .000 & 86.000 .000 \\
\hline Jmset (Rp) & 446.500 .000 & 505.800 .000 & 397.800 .000 \\
\hline $\mathrm{ROI}(\%)$ & 0,035 & 122,05 & 62,86 \\
\hline
\end{tabular}


produksi dan juga pendapatan. Hal ini mengakibatkan banyaknya modal yang diterima juga berpengaruh terhadap kesiapan pelaku UMKM dalam menjalankan usahanya. Apabila modal dan tenaga kerja meningkat maka produktivitas dan pendapatan juga akan meningkat (Sukirno, 2009).

Faktor kedua yang mempengaruhi pendapatan UMKM adalah biaya produksi. Menurut (Sukirno, 2009:208) analisis mengenai biaya produksi perusahaan perlu dibedakan menjadi dua jangka waktu yaitu: jangka pendek dan jangka panjang.. Biaya produksi dapat difefinisikan sebagai semua pengeluaran yang dilakukan oleh prusahaan untuk memproleh faktorfaktor produksi dan bahan-bahan mentah yang akan digunakan untuk menciptakan barang-barang yang diproduksikan perusahaan tersebut. Biaya produksi yang dikeluarkan oleh setiap perusahaan dapat dibedakan menjadi dua jenis: biaya eksplisit dan biaya tersembunyi. (Anwar 2009: 92) mengemukakan bahwa jika biaya-biaya yang digunakan oleh perusahaan bisa dikelola dengan baik dan dengan cara yang ekonomis, maka hasil produksi akan dapat ditingakatkan, biaya produksi dapat menurun dan hal tersebut dapat mempengaruhi meningkatnya pendapatan yang diperoleh dari hasil penjualan.

Faktor ketiga yang dapat mempengaruhi pendapatan UMKM adalah jumlah tenaga kerja. Menurut (Mahayasa \& Yuliarmi, 2017:110) Tenaga kerja dikatakan sebagai sumber daya terpenting dalam rangka pengembangan kualitas produk suatu UMKM dan layanan terhadap konsumen dengan tujuan untuk memberikan kontribusi yang signifikan terhadap pembangunan perekonomian suatu negara serta proses produksi dari industri itu sendiri. Perusahaan yang termasuk kedalam industri mikro kecil adalah perusahaan industri yang mempunyai tenaga kerja 1-9 orang.

Faktor keempat yang dapat mempengaruhi pendapatan UMKM adalah tingkat pendidikan. Sejauh 
Publish by: Library of STKIP PGRI Sumatera Barat

E-ISSN : 2775-5770

Vol. 1 No. 2 (Mei 2021) (367-383)

http://ejournal.stkip-pgri-sumbar.ac.id/index.php/horizon

menyangkut pola investasi dibidang pendidikan (Jhingan, 2010:418) mengemukakan bahwa rakyat berpendidikan menengah ini yang menyediakan keterampilan penting yang paling banyak dibutuhkan bagi pembangunan ekonomi.

Berdasarkan uraian diatas penelitian ini mengambil judul "Pengaruh Modal, Biaya Produksi, Jumlah Tenaga Kerja, dan Tingkat Pendidikan Terhadap Pendapatan UMKM Sektor Kuliner Di Kecamatan Lubuk Begalung Kota Padang".

\section{METODE PENELITIAN}

Jenis penelitian yang digunakan yaitu penelitian asosiatif. Populasi dalam penelitian ini adalah

pelaku UMKM sektor kuliner di Kecamatan Lubuk Begalung Kota Padang. Klaster usaha berdasarkan penggunaan modal di kecamatan Lubuk Begalung Kota Padang pada tahun 2017 dapat dibagi menjadi 2 klaster yaitu modal mikro dengan jumlah usaha 974 unit dan modal kecil dengan jumlah usaha 81 unit. Pembagian klaster usaha tersebut berdasarkan data yang didapatkan dari dinas koperasi dan UMKM Kota Padang. Teknik pengambilan sampel yang diinginkan dalam penelitian ini adalah Stratified Random Sampling. Jadi $n$ keseluruhannya yaitu $82+42=$ 124. Analisa data menggunakan uji regresi linear berganda.

HASIL DAN PEMBAHASAN

Tabel 2. Hasil Regresi Linear Berganda Pendapatan UMKM

Dependent Variable: $Y$

Method: Least Squares

Date: 09/12/20 Time: 20:17

Sample: 1124

Included observations: 124

\begin{tabular}{ccccc}
\hline \hline Variable & Coefficient & Std. Error & t-Statistic & Prob. \\
\hline \hline C & -9046303. & 4825310. & -1.874761 & 0.0633 \\
X1 & 0.024297 & 0.078702 & 0.308716 & 0.7581 \\
X2 & 0.153925 & 0.056519 & 2.723395 & 0.0074 \\
X3 & 6017622. & 1868268. & 3.220963 & 0.0016
\end{tabular}

371 | Windri Oktaviana, Ansofino, Yosi Eka Putri 1/ JHP, Vol. 1 No. 2, 2021 
Publish by: Library of STKIP PGRI Sumatera Barat

E-ISSN : 2775-5770

Vol. 1 No. 2 (Mei 2021) (367-383)

http://ejournal.stkip-pgri-sumbar.ac.id/index.php/horizon

\begin{tabular}{lrllr}
\multicolumn{1}{c}{ X4 } & 2894974. & 446224.9 & 6.487701 & 0.0000 \\
\hline \hline R-squared & 0.647268 & Mean dependent var & 41367290 \\
Adjusted R-squared & 0.635412 & S.D. dependent var & 20585181 \\
S.E. of regression & 12429568 & Akaike info criterion & 35.54854 \\
Sum squared resid & $1.84 E+16$ & Schwarz criterion & 35.66226 \\
Log likelihood & -2199.010 & Hannan-Quinn criter & 35.59474 \\
F-statistic & 54.59171 & Durbin-Watson stat & 1.877222 \\
Prob(F-statistic) & 0.000000 & & & \\
\hline
\end{tabular}

Sumber: Olahan Data Primer, 2020

Adapun persamaan regresi

linear berganda pada sampel total adalah sebagai berikut :

$$
\mathrm{Y}=\mathrm{a}+\mathrm{b} 1 \mathrm{X} 1+\mathrm{b} 2 \mathrm{X} 2+\mathrm{b} 3 \mathrm{X} 3
$$

$+\mathrm{b} 4 \mathrm{X} 4$

$$
\begin{aligned}
& Y=-9046303+0,024297 X 1 \\
& +0,153925 X 2+6017622 X 3+ \\
& 2894974 X 4
\end{aligned}
$$

Berdasarkan persamaan diatas diperoleh uraian sebagai berikut :

1. Nilai koefisien regresi $\left(\mathrm{X}_{1}\right)$ modal usaha sebesar 0.024297, artinya jika modal usaha naik sebesar satu satuan, maka pendapatan naik sebesar 0.024297 kali untuk setiap satuannya, dengan asumsi variabel lain tidak mengalami perubahan atau konstan. Sementara nilai $\mathrm{t}_{\text {-statistik }}$ modal usaha $0.308716<\mathrm{t}^{-}$tabel sebesar 1.98 artinya modal usaha berpengaruh positif dan tidak signifikan terhadap pendapatan pada pelaku Usaha Mikro, Kecil dan Menengah (UMKM) sektor kuliner di Kecamatan Lubuk Begalung Kota Padang Provinsi Sumatera Barat, dengan demikian $\mathrm{H}_{\mathrm{o}}$ diterima dan $\mathrm{H}_{\mathrm{a}}$ ditolak.

2. Nilai koefisien regresi $\left(\mathrm{X}_{2}\right)$ Biaya produksi sebesar 0.153925 , artinya jika biaya produksi naik sebesar satu satuan, maka pendapatan meningkat sebesar 0.153925 kali untuk setiap satuannya, dengan asumsi variabel lain tidak mengalami perubahan atau konstan. Sementara nilai $\mathrm{t}_{\text {-statistik }}$ Biaya produksi $2.723395>\mathrm{t}$-tabel sebesar 1,98 artinya biaya produksi berpengaruh positif 
dan signifikan terhadap

pendapatan terhadap pendapatan pada pelaku Usaha Mikro, Kecil dan Menengah (UMKM) sektor kuliner di Kecamatan Lubuk Begalung Kota Padang Provinsi Sumatera Barat, dengan demikian, $\mathrm{H}_{\mathrm{o}}$ ditolak dan $\mathrm{H}_{\mathrm{a}}$ diterima.

3. Nilai koefisien regresi $\left(\mathrm{X}_{3}\right)$ jumlah tenaga kerja sebesar 6017622, artinya jika biaya produksi naik sebesar satu satuan, maka pendapatan meningkat sebesar 6017622 untuk setiap satuannya, dengan asumsi variabel lain tidak mengalami perubahan atau konstan. Sementara nilai $\mathrm{t}_{\text {-statistik }}$ jumlah tenaga kerja $3.220963>$ $\mathrm{t}$-tabel sebesar 1,98 artinya jumlah tenaga kerja berpengaruh positif dan signifikan terhadap pendapatan terhadap pendapatan pada pelaku Usaha Mikro, Kecil dan Menengah (UMKM) sektor kuliner di Kecamatan Lubuk
Begalung Kota Padang Provinsi Sumatera Barat, dengan demikian, $\mathrm{H}_{\mathrm{o}}$ ditolak dan $\mathrm{H}_{\mathrm{a}}$ diterima.

4. Nilai koefisien regresi $\left(\mathrm{X}_{4}\right)$ tingkat pendidikan sebesar 2894974, artinya jika tingkat pendidikan meningkat sebesar satu satuan, maka pendapatan meningkat sebesar 2894974 kali untuk setiap satuannya, dengan asumsi variabel lain tidak mengalami perubahan atau konstan. Sementara nilai $\mathrm{t}_{\text {-statistik }}$ tingkat pendidikan 6.487701> ttabel sebesar 1,98 artinya tingkat pendidikan berpengaruh positif dan signifikan terhadap pendapatan terhadap pendapatan pada pelaku Usaha Mikro, Kecil dan Menengah (UMKM) sektor kuliner di Kecamatan Lubuk Begalung Kota Padang Provinsi Sumatera Barat, dengan demikian, $\mathrm{H}_{\mathrm{o}}$ ditolak dan $\mathrm{H}_{\mathrm{a}}$ diterima. 
Tabel 3. Hasil Regresi Faktor Yang Mempengaruhi Pendapatan UMKM Berdasarkan Klaster Usaha

\begin{tabular}{lccrc}
\hline \multirow{2}{*}{ Variabel } & \multicolumn{2}{c}{ Modal Mikro } & \multicolumn{2}{c}{ Modal Kecil } \\
\cline { 2 - 5 } & Coefficient & t-Statistic & Coefficient & t-Statistic \\
\hline Modal & 0.455974 & 4.508856 & 0.253589 & 2.029458 \\
\hline Biaya produksi & 1.593910 & 9.139478 & 0.414613 & 4.757485 \\
\hline Jumlah Tenaga Kerja & 3981416. & 1.911951 & 5876951. & 2.300887 \\
\hline Tingkat Pendidikan & 637554.9 & 2.223903 & 2145507. & 2.358697 \\
\hline
\end{tabular}

Sumber: Olahan Data Primer, 2020

Adapun persamaan regresi linear pada sampel modal mikro adalah sebagai berikut :

$\mathrm{Y}=\mathrm{a}+\mathrm{b} 1 \mathrm{X} 1+\mathrm{b} 2 \mathrm{X} 2+\mathrm{b} 3 \mathrm{X} 3+$ b4X4

$\mathrm{Y}=-10053021+0,455974 \mathrm{X} 1+$

$1,593910 \mathrm{X} 2+3981416 \mathrm{X} 3+$ 637554,9X4

Adapun persamaan regresi linear pada sampel modal kecil adalah sebagai berikut :

$\mathrm{Y}=\mathrm{a}+\mathrm{b} 1 \mathrm{X} 1+\mathrm{b} 2 \mathrm{X} 2+\mathrm{b} 3 \mathrm{X} 3+$ b4X4

$\mathrm{Y}=-46442912+0,253589 \mathrm{X} 1+$ $0,414613 \mathrm{X} 2+5876951 \mathrm{X} 3+$ 2145507X4

Berdasarkan hasil analisis regresi linier berganda yang disajikan pada tabel diatas, dapat diketahui bahwa nilai koefesien regresi pada modal usaha mikro sebesar 0.455974 yang berarti bahwa apabila modal usaha mikro meningkat sebesar 1 persen, maka pendapatan usaha mikro meningkat pula sebesar 0.455974 rupiah dengan asumsi variable lain tidak mengalami perubahan atau konstan. Sementara nilai $\mathrm{t}$-statistik modal usaha mikro $4.508856>t^{-}$tabel sebesar 1.99 artinya modal usaha mikro berpengaruh postif dan signifikan terhadap pendapatan pada pelaku Usaha Mikro, Kecil dan Menengah (UMKM) sektor kuliner di Kecamatan Lubuk Begalung Kota Padang Provinsi Sumatera Barat, dengan demikian $\mathrm{H}_{\mathrm{o}}$ ditolak dan $\mathrm{H}_{\mathrm{a}}$ diterima.

Nilai koefesien regresi pada modal usaha kecil sebesar 0.253589 yang berarti bahwa apabila modal usaha kecil meningkat sebesar 1 persen, maka pendapatan usaha kecil meningkat pula sebesar 0.253589 
rupiah dengan asumsi variabel lain tidak mengalami perubahan atau konstan. Sementara nilai $t$-statistik modal usaha kecil 2.029458> t-tabel sebesar 2,02 artinya modal usaha kecil berpengaruh postif dan signifikan terhadap pendapatan pada pelaku Usaha Mikro, Kecil dan Menengah (UMKM) sektor kuliner di Kecamatan Lubuk Begalung Kota Padang Provinsi Sumatera Barat, dengan demikian $\mathrm{H}_{\mathrm{o}}$ ditolak dan $\mathrm{H}_{\mathrm{a}}$ diterima.

Nilai koefesien regresi pada biaya produksi usaha mikro sebesar 1.593910 yang berarti bahwa apabila biaya produksi usaha mikro meningkat sebesar 1 persen, maka pendapatan usaha mikro meningkat pula sebesar 1.593910 rupiah dengan asumsi variable lain tidak mengalami perubahan atau konstan. Sementara nilai $\mathrm{t}$-statistik modal usaha mikro $9.139478>t^{-}$tabel sebesar 1.99 artinya biaya produksi usaha mikro berpengaruh postif dan signifikan terhadap pendapatan pada pelaku Usaha Mikro, Kecil dan Menengah (UMKM) sektor kuliner di
Kecamatan Lubuk Begalung Kota Padang Provinsi Sumatera Barat, dengan demikian $\mathrm{H}_{\mathrm{o}}$ ditolak dan $\mathrm{H}_{\mathrm{a}}$ diterima.

Nilai koefesien regresi pada biaya produksi usaha kecil sebesar 0.414613 yang berarti bahwa apabila biaya produksi usaha kecil meningkat sebesar 1 persen, maka pendapatan usaha kecil meningkat pula sebesar 0.414613 rupiah dengan asumsi variabel lain tidak mengalami perubahan atau konstan. Sementara nilai $\mathrm{t}$-statistik biaya produksi usaha kecil $4.757485>\mathrm{t}$-tabel sebesar 2,02 artinya biaya produksi usaha kecil berpengaruh postif dan signifikan terhadap pendapatan pada pelaku Usaha Mikro, Kecil dan Menengah (UMKM) sektor kuliner di Kecamatan Lubuk Begalung Kota Padang Provinsi Sumatera Barat, dengan demikian $\mathrm{H}_{\mathrm{o}}$ ditolak dan $\mathrm{H}_{\mathrm{a}}$ diterima.

Nilai koefesien regresi pada jumlah tenaga kerja usaha mikro sebesar 3981416 yang berarti bahwa apabila jumlah tenaga kerja usaha mikro meningkat sebesar 1 persen, 
maka pendapatan usaha mikro meningkat pula sebesar 3981416 rupiah dengan asumsi variable lain tidak mengalami perubahan atau konstan. Sementara nilai $\mathrm{t}_{\text {-statistik }}$ jumlah tenaga kerja usaha mikro $1.911951<\mathrm{t}_{\text {tabel }}$ sebesar 1.99 artinya jumlah tenaga kerja usaha mikro berpengaruh postif dan tidak signifikan terhadap pendapatan pada pelaku Usaha Mikro, Kecil dan Menengah (UMKM) sektor kuliner di Kecamatan Lubuk Begalung Kota Padang Provinsi Sumatera Barat, dengan demikian $\mathrm{H}_{\mathrm{o}}$ ditolak dan $\mathrm{H}_{\mathrm{a}}$ diterima.

Nilai koefesien regresi pada jumlah tenaga kerja usaha kecil sebesar 5876951 yang berarti bahwa apabila biaya produksi usaha kecil meningkat sebesar 1 persen, maka pendapatan usaha kecil meningkat pula sebesar 5876951 rupiah dengan asumsi variabel lain tidak mengalami perubahan atau konstan. Sementara

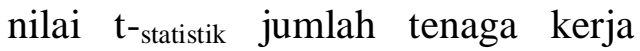
usaha kecil $2.300887>\mathrm{t}$-tabel sebesar 2,02 artinya jumlah tenaga kerja usaha kecil berpengaruh postif dan signifikan terhadap pendapatan pada pelaku Usaha Mikro, Kecil dan Menengah (UMKM) sektor kuliner di Kecamatan Lubuk Begalung Kota Padang Provinsi Sumatera Barat, dengan demikian $\mathrm{H}_{\mathrm{o}}$ ditolak dan $\mathrm{H}_{\mathrm{a}}$ diterima.

Nilai koefesien regresi pada tingkat pendidikan usaha mikro sebesar 637554.9 yang berarti bahwa apabila jumlah tenaga kerja usaha mikro meningkat sebesar 1 persen, maka pendapatan usaha mikro meningkat pula sebesar 637554.9 rupiah dengan asumsi variable lain tidak mengalami perubahan atau konstan. Sementara nilai $\mathrm{t}$-statistik tingkat pendidikan usaha mikro $2.223903<\mathrm{t}$-tabel sebesar 1.99 artinya tingkat pendidikan usaha mikro berpengaruh postif dan signifikan terhadap pendapatan pada pelaku Usaha Mikro, Kecil dan Menengah (UMKM) sektor kuliner di Kecamatan Lubuk Begalung Kota Padang Provinsi Sumatera Barat, dengan demikian $\mathrm{H}_{\mathrm{o}}$ ditolak dan $\mathrm{H}_{\mathrm{a}}$ diterima. 
Nilai koefesien regresi pada tingkat pendidikan usaha kecil sebesar 2145507 yang berarti bahwa apabila tingkat pendidikan usaha kecil meningkat sebesar 1 persen, maka pendapatan usaha kecil meningkat pula sebesar 2145507 rupiah dengan asumsi variabel lain tidak mengalami perubahan atau konstan. Sementara nilai $\mathrm{t}$-statistik tingkat pendidikan usaha kecil $2.358697>t$-tabel sebesar 2,02 artinya tingkat pendidikan usaha kecil berpengaruh postif dan signifikan terhadap pendapatan pada pelaku Usaha Mikro, Kecil dan Menengah (UMKM) sektor kuliner di Kecamatan Lubuk Begalung Kota Padang Provinsi Sumatera Barat, dengan demikian $\mathrm{H}_{\mathrm{o}}$ ditolak dan $\mathrm{H}_{\mathrm{a}}$ diterima.

a. Pengaruh Modal $\left(\mathrm{X}_{1}\right)$ Terhadap Pendapatan UMKM Sektor Kuliner (Y) Di Kecamatan Lubuk Begalung Kota Padang

Berdasarkan data yang didapatkan dilapangan, variabel modal usaha pada klaster mikro menunjukan nilai koefesien regresi pada modal usaha mikro sebesar
0.455974 dengan nilai tstatistik $4.508856>\mathrm{t}_{\text {tabel }}$ sebesar 1.99 dengan $\mathrm{df}=77$. Sementara pada klaster kecil nilai koefesien regresi pada modal usaha kecil sebesar 0.253589 dan nilai $t$-statistik modal usaha kecil 2.029458> t-tabel sebesar 2,02 dengan $\mathrm{df}=37$. Hal ini mengandung arti bahwa Ho ditolak dan Ha diterima, dengan demikian terbukti bahwa variabel modal usaha pada klaster mikro dan kecil memiliki pengaruh positif dan signifikan terhadap pendapatan pendapatan pada pelaku Usaha Mikro, Kecil dan Menengah (UMKM) sektor kuliner di Kecamatan Lubuk Begalung Kota Padang Provinsi Sumatera Barat.

Pengaruh modal terhadap pendapatan UMKM Menurut (Setiaji \& Fatuniah, 2018:4) bahwa modal adalah uang yang tidak dibelanjakan, jadi disimpan kemudian diinvestasikan. Maka dari itu, dengan meningkatkan jumlah modal yang digunakan maka juga akan meningkatkan pendapatan karena semakin tinggi modal yang 
digunakan maka akan menentukan pendapatan yang diperoleh sebab usaha yang akan dirintis akan luas dengan adanya modal yang bsar. Sehingga dapat disimpulkan bahwa semakin besar modal maka akan dapat menambah atau meningkatkan jumlah poduktifitas sehingga dapat meningkatkan penjualan dan juga meningkatkan pendapatan.

Hasil penelitian ini sejalan dengan penelitian (Setiaji \& Fatuniah, 2018) tentang Pengaruh modal, lama usaha dan lokasi terhadap pendapatan pedagang pasar pasca relokasi diperoleh hasil terdapat pengaruh modal terhadap pendapata pedagang.

b. Pengaruh Biaya produksi $\left(\mathrm{X}_{2}\right)$ Terhadap Pendapatan UMKM Sektor Kuliner (Y) Di Kecamatan Lubuk Begalung Kota Padang

Berdasarkan data, variabel biaya produksi pada klaster mikro menunjukan 1.593910 sementara nilai $\mathrm{t}$-statistik modal usaha mikro $9.139478>\mathrm{t}$-tabel sebesar 1.99, dimana nilai $t$-tabel diperoleh dari rumus $\mathrm{df}=\mathrm{n}-\mathrm{k}-1$ yaitu $82-4-1=77$ dengan derajat kemaknaan 0,05 diperoleh nilai $\mathrm{t}_{\text {-tabel }} 1,99$. Sementara pada klaster kecil koefisien regresi 0.414613 dengan nilai $\mathrm{t}_{\text {-statistik }}$ biaya produksi usaha kecil $4.757485>\mathrm{t}$ tabel sebesar 2,02 dengan df= Yitu 424-1=37 dengan derajat kemaknaan 0,05 diperoleh nilai $t$-tabel 2,02, artinya biaya produksi usaha mirko dan kecil berpengaruh postif dan signifikan terhadap pendapatan pada pelaku Usaha Mikro, Kecil dan Menengah (UMKM) sektor kuliner di Kecamatan Lubuk Begalung Kota Padang Provinsi Sumatera Barat, dengan demikian $\mathrm{H}_{\mathrm{o}}$ ditolak dan $\mathrm{H}_{\mathrm{a}}$ diterima. Dengan demikian terbukti bahwa variabel biaya produksi pada klaster mikro dan kecil memiliki pengaruh positif dan signifikan terhadap pendapatan UMKM sektor kuliner di Kecamatan Lubuk Begalung Kota Padang Provinsi Sumatera Barat.

Pengaruh biaya produksi terhadap pendapatan menurut Carter dalam (Mulyana, 2017:188) adalah "tingkat laba yang diperoleh perusahaan dapat ditentukan oleh volume produksi yang dihasilkan, semakin banyak volume produksi 
yang dicapai maka semakin tinggi pula biaya produksi”. Berdasarkan teori tersebut, menjelaskan bahwa biaya produksi mempengaruhi laba, dimana ketika biaya produksi ditingkatkan maka akan menambah volume produksi yang nantinya akan mempengaruhi tingkat laba yang diperoleh perusahaan. Dengan demikian, semakin besar biaya produksi yang dikeluarkan, maka jumlah produksi yang dihasilkan juga akan semakin besar yang pada nantinya akan meningkatkan pendapatan perusahaan.

Hasil penelitian ini sejalan dengan penelitian sebelumnya yang dilakukan oleh (Purnomo et al., 2018) tentang Pengaruh Biaya Produksi, Lama Usaha, Produktivitas Terhadap Pendapatan Petani Salak Pondoh Di Desa Pronojiwo Kecamatan Pronojiwo Kabupaten Lumajang diperoleh hasil terdapat pengaruh biaya prroduksi terhadap pendapatan petani.

c. Pengaruh Jumlah Tenaga Kerja $\left(\mathrm{X}_{3}\right)$ Terhadap Pendapatan UMKM Sektor Kuliner (Y) Di Kecamatan Lubuk Begalung Kota Padang
Berdasarkan data yang didapatkan dilapangan, variable jumlah tenaga kerja pada klaster mikro menunjukan 3981416 sementara nilai $\mathrm{t}$-statistik jumlah tenaga kerja usaha mikro $1.911951<\mathrm{t}$-tabel dengan $\mathrm{df}=77$ sebesar 1.99 artinya jumlah tenaga kerja usaha mikro berpengaruh postif dan tidak signifikan terhadap pendapatan pada pelaku Usaha Mikro, Kecil dan Menengah (UMKM) sektor kuliner di Kecamatan Lubuk Begalung Kota Padang Provinsi Sumatera Barat, dengan demikian $\mathrm{H}_{\mathrm{o}}$ ditolak dan $\mathrm{H}_{\mathrm{a}}$ diterima. Sedangkan nilai koefesien regresi pada jumlah tenaga kerja usaha kecil sebesar 5876951 dengan nilai $\mathrm{t}_{\text {-statistik }}$ jumlah tenaga kerja usaha kecil $2.300887>\mathrm{t}$-tabel dengan $\mathrm{df}=37$ sebesar 2,02 artinya jumlah tenaga kerja usaha kecil berpengaruh postif dan signifikan terhadap pendapatan pada pelaku Usaha Mikro, dengan demikian $\mathrm{H}_{\mathrm{o}}$ ditolak dan $\mathrm{H}_{\mathrm{a}}$ diterima. Hal ini menunjukan bahwa pada klaster mikro tidak terdapat pengaruh jumlah tenaga kerja terhadap pendapatan akan 
tetapi pada klaster kecil terdapat pengaruh jumlah tenaga kerja terhadap pendapatan pada pelaku Usaha Mikro, Kecil dan Menengah (UMKM) sektor kuliner di Kecamatan Lubuk Begalung Kota Padang Provinsi Sumatera Barat.

Pengelolaan tenaga kerja yang belum maksimal akan mengakibatkan pemborosan (inefisiensi) dalam bekerja. Dalam usaha memenuhi permintaan pasar, maka setiap pengusaha perlu mengatur waktu kerja para karyawan secara lebih tepat dan memperhatikan kualitas tenaga kerja guna menghasilkan produk sesuai yang diharapkan sehingga dapat meningkatkan pendapatan para pengusaha tersebut (Mahayasa \& Yuliarmi, 2016:22).

Hasil penelitian ini sejalan dengan penelitian sebelumnya yang dilakukan oleh (Mahayasa \& Yuliarmi, 2017) tentang Pengaruh Modal, Teknologi dan Tenaga Kerja Terhadap Produksi dan Pendapatan Usaha Kerajinan Ukiran Kayu di Kecamatan Tembuku diperoleh terdapat pengaruh jumlah tenaga kerja terhadap pendapatan.

d. Pengaruh Tingkat Pendidikan $\left(\mathrm{X}_{4}\right)$ Terhadap Pendapatan UMKM Sektor Kuliner (Y) Di Kecamatan Lubuk Begalung Kota Padang

Berdasarkan data yang didapatkan dilapangan, variabel tingkat pendidikan pada klaster mikro menunjukan nilai koefesien regresi pada tingkat pendidikan usaha mikro sebesar 637554.9 dengan $\mathrm{t}_{\text {hitung }} 2.223903<\mathrm{t}$-tabel dengan $\mathrm{df}=77$ sebesar 1.99 artinya tingkat pendidikan usaha mikro berpengaruh postif dan signifikan terhadap pendapatan pada pelaku Usaha Mikro, Kecil dan Menengah (UMKM) sektor kuliner di Kecamatan Lubuk Begalung Kota Padang Provinsi Sumatera Barat, dengan demikian $\mathrm{H}_{\mathrm{o}}$ ditolak dan $\mathrm{H}_{\mathrm{a}}$ diterima. Pada klaster kecil diperoleh nilai koefesien regresi sebesar 2145507 sementara nilai tstatistik $2.358697>t$-tabel dengan $\mathrm{df}=37$ sebesar 2,02 artinya tingkat pendidikan usaha kecil berpengaruh postif dan signifikan terhadap pendapatan pada pelaku Usaha 
Mikro dengan demikian $\mathrm{H}_{\mathrm{o}}$ ditolak dan $\mathrm{H}_{\mathrm{a}}$ diterima. Hal ini menunjukan bahwa pada tingkat pendidikan klaster kecil memiliki pengaruh terhadap pendapatan sedangkan pada klaster mikro tidak terdapat pengaruh tingkat pendidikan terhadap pendapatan ada pelaku Usaha Mikro, Kecil dan Menengah (UMKM) sektor kuliner di Kecamatan Lubuk Begalung Kota Padang Provinsi Sumatera Barat.

Pengaruh tingkat pendidikan menurut (Atmanti, 2001:30-39) yaitu Pendidikan merupakan suatu bentuk investasi dalam bidang sumber daya manusia yang berperan dalam memacu pertumbuhan ekonomi. Investasi ini merupakan investasi jangka panjang karena manfaatnya baru dapat dirasakan setelah sepuluh tahun.Menurut (Simanjuntak, 2001:32) hubungan tingkat pendidikan pada tingkat pendapatan yaitu karena mengasumsikan bahwa semakin tinggi tingkat pendidikan maka akan semakin tinggi pula tingkat produktivitas karyawan yang pada akhirnya mempengaruhi pendapatan.

Berdasarkan hasil penelitian (Utari, 2014) terhadap UMKM di Kawasan Imam Bonjol Denpasar Barat menunujukan bahwa tingkat pendidikan secara parsial berpengaruh positif terhadap pendapatan UMKM dimana, semakin tinggi tingkat pendidikan maka semakin tinggi tingkat pendapatan yang diterima oleh UMKM.

e. Perbandingan Faktor-faktor yang mempengaruhi Pendapatan UMKM sektor kuliner berdasarkan kelompok sampel modal mikro dan modal kecil di kecamatan Lubuk Begalung Kota Padang

Perbandingan faktor-faktor yang mempengaruhi Nilai pendapatan UMKM sektor kuliner bertujuan untuk membuktikan secara empiris variabel independen yang sangat berpengaruh diantara dua kelompok sampel modal yang dikategorikan berdasarkan modal mikro dan modal kecil.

\section{KESIMPULAN}

Berdasarkan pokok persoalan yang telah dibagi dan pembahasan 
yang telah dilakukan, maka dapat dirumuskan kesimpulan sebagai berikut:

1. Modal usaha berpengaruh positif dan signifikan terhadap pendapatan UMKM sektor kuliner di Kecamatan Lubuk Begalung Kota Padang Provinsi Sumatera Barat. Pengaruh yang lebih besar terdapat pada kelompok usaha mikro.

2. Biaya produksi berpengaruh positif dan signifikan terhadap pendapatan UMKM sektor kuliner di Kecamatan Lubuk Begalung Kota Padang Provinsi Sumatera Barat.

3. Jumlah tenaga kerja berpengaruh positif dan tidak signifikan terhadap pendapatan UMKM sektor kuliner di Kecamatan Lubuk Begalung Kota Padang Provinsi Sumatera Barat pada klaster mikro dan berpengaruh positif dan signifikan pada klaster kecil. Pengaruh yang lebih besar terdapat pada kelompok usaha kecil.
4. Tingkat pendidikan berpengaruh positif dan signifikan terhadap pendapatan UMKM sektor kuliner di Kecamatan Lubuk Begalung Kota Padang Provinsi Sumatera Barat. Pengaruh yang lebih besar terdapat pada kelompok usaha mikro.

5. Terdapat pengaruh secara bersama-sama modal, biaya produksi, jumlah tenaga ekrja dan tingkat pendidikan terhadap pendapatan UMKM sektor kuliner di Kecamatan Lubuk Begalung Kota Padang Provinsi Sumatera Barat.

\section{DAFTAR PUSTAKA}

Ansofino. (2016a). Ekonometrika. Deepublish.

Ansofino. (2016b). Integrasi Perekonomian Kabupaten Dan Kota Di Sumatera Barat Menuju Integrasi Pasar Untuk Menghadapi Masyarakat Ekonomi ASEAN 2015. Jurnal Ekonomi, 9(2), 137-154.

Ansofino. (2019). Integrated Carrying Capacity of the Marine Tourism Area and Small Island of Mandeh Region and Their Impact on Economic Growth. Vol. 8, No. 1, 
Vol. 1 No. 2 (Mei 2021) (367-383)

http://ejournal.stkip-pgri-sumbar.ac.id/index.php/horizon

2019,

$\mathrm{pp}$

$35-$

43.doi:10.11648/j.eco.20190801.15

Ansofino, dkk. (2020). The Tourism

Destination Competitiveness:

Using The Promethee GAIA

Model.https://doi.org/ 10.22202/

economica.2020.v9.i1.4063

Atmanti, D. H. (2001). Investasi

Sumber Daya Manusia Melalui

Pendidikan.

Dinamika

Pembangunan, 2(1), 30-39.

Bambang, R. (2010). Dasar-Dasar

Pembelajaran Perusahaan.

BPFE.

Jhingan, M. L. (2010). EKONOMI PEMBANGUNAN DAN

PERENCANAAN.

PT

RAJAGRAFINDO PERSADA.

Kasmir. (2011). Analisis Laporan

Keuangan. Rajawali Press.

Mahayasa, I. B. A., \& Yuliarmi, N. N. (2017). Pengaruh Modal, Teknologi dan Tenaga Kerja Terhadap Produksi dan Pendapatan Usaha Kerajinan Ukiran Kayu di Kecamatan Tembuku. EP UNUD, 6(8), 1510-1543.

Mulyana, A. (2017). Pengaruh Biaya Promosi Terhadap Laba Usaha Samsung Co Tahun 2009-2015. Jurnal Manajemen Indonesia,

Purnomo, A., Fathorrazi, M., \& Viphindrartin, S. (2018). Pengaruh Biaya Produksi , Lama Usaha , Produktivitas
Terhadap Pendapatan Petani

Salak Pondoh Di Desa Pronojiwo Kecamatan Pronojiwo Kabupaten Lumajang ( The Effect of Costs Production , Years Of Farming, Productivity to the Income of the Farmers of Pondoh. EJournal Ekonomi Bisnis Dan Akuntansi, V(1), 44-47.

Setiaji, K., \& Fatuniah, A. L. (2018). Pengaruh Modal, Lama Usaha dan Lokasi Terhadap Pendapatan Pedagang Pasar Pasca Relokasi. Pendidikan Ekonomi Dan Bisnis, 6(1), 177.

Simanjuntak, P. (2001). Pengantar Ekonomi Sumber Daya Manusia. Fakultas Ekonomi UI.

Sukirno, S. (2006). Ekonomi Pembangunan: Proses, Masalah Dan Dasar Kebijakan. Kencana.

Sukirno, $\mathrm{S}$. (2009). MAKROEKONOMI TEORI PENGANTAR. PT RAJAGRAFINDO PERSADA.

Utari, T. (2014). Pengaruh Modal Tingkat Pendidikan Dan Teknologi Terhadap Pendapatan Usaha Mikro Kecil Dan Menengah (UMKM) Di Kawasan Imam Bonjol Denpasar Barat. EP UNUD, 3(12), 576-585. 